\title{
LÍNGUA E CULTURA DO BRASIL. PRESENÇA EM CUBA
}

Maria de los Angeles Pupo Brinas ${ }^{1}$

\begin{abstract}
RESUMO
Esse artigo apresenta uma experiência cubana de ensino de português-língua estrangeira (PLE) numa nova etapa da política educacional realizada em Cuba. Trata-se de uma revolução cultural cujo objetivo fundamental é a aquisição de uma cultura geral integral por parte da população. Para tanto foi criado um programa televisivo chamado Universidade para Todos no canal educativo que incluiu cursos de línguas estrangeiras que contribuem àquele objetivo.
\end{abstract}

Palavras-chave: português-língua estrangeira, Universidade para Todos, curso televisivo, cultura geral integral.

A aquisição de uma Língua Estrangeira seria impulsionada, comumente, por razões sócio-culturais, em determinados momentos históricos. Língua e Cultura são inseparáveis. Em concordância com Hymes (1972), as estruturas lingüísticas e sociais estão tão estreitamente vinculadas que é necessário estudá-las simultaneamente, portanto, toda língua está vinculada à cultura que expressa e transmite, sendo impossível separá-las.

Ao falarmos da presença da Língua e Cultura do Brasil em Cuba visamos apresentar uma experiência que se constituiu referência. Por isso, o nosso objetivo é compartilhar o resultado de um trabalho que demonstra essa presença em Cuba. Trata-se de um curso de português ministrado em 2004 pela primeira vez no país.

Em fevereiro de 2004 começou a ser transmitido um curso televisivo de português, que seria o primeiro desse tipo, estendendo-se por oito meses e ocupando um lugar de destaque a nível nacional. Esse curso foi dirigido a toda a população e difundido pelo Programa Universidade para Todos através do Canal Educativo da televisão cubana. É um resultado dos novos programas educativos, produto da profunda revolução cultural que tem se efetivado em Cuba nos últimos anos. Para tanto foram criados mais de 100 novos programas educativos com o objetivo de que a população alcance uma cultura geral integral. Esse conceito foi definido e proclamado como objetivo fundamental. Nesse sentido declara-se que:

La cultura debe ser integral, no podría concebirse sin cultura política, ni ésta sin conocimientos de la historia universal, su desarrollo, sus frutos y enseñanzas; sin conocimientos de la política internacional y la economía

\footnotetext{
${ }^{1}$ Maria de los Angeles Pupo Brinas é mestre em lingüística aplicada, licenciada em língua e literatura russa e professora de português da Faculdade de Línguas Estrangeiras da Universidade de Havana
} 
mundial, sin conocimientos básicos de las principales corrientes filosóficas desarrolladas por el hombre, así como los avances de la ciencia moderna y sus probables consecuencias éticas y sociales. Nos limitamos con esto a citar sólo algunos conceptos, todavía en desarrollo, de lo que debe calificarse como la masificación de la cultura general e integral; en fin, los conocimientos mínimos que cada ciudadano de nuestro país debe alcanzar. ${ }^{2}$

O Programa Universidade para Todos no Canal Educativo iniciou as tele-aulas em 2 de outubro de 2000 e com a ajuda dele, a população tem tido acesso a mais de 50 cursos, com mais de 2000 horas na TV, sem incluir as retransmissões. Calcula-se em mais de 500 o número de docentes que têm ministrado as aulas. Universidade para todos incluiu idiomas estrangeiros como inglês, francês, português, italiano e posteriormente alemão. Todos com um adequado nível lingüístico e pedagógico e grande aceitação por parte da população.

De acordo com a Dra . Dolores Corona, várias ideologias subjazem às políticas lingüísticas. Trata-se de um sistema de idéias e opiniões de uma sociedade determinada, num momento histórico concreto, acerca da função que desempenham uma ou várias línguas. Nesse sentido, referiu-se à existência de determinadas políticas lingüísticas educacionais em cada país, determinadas por condições políticas, econômicas e sociais concretas. Deste modo podemos mencionar três blocos de ideologias lingüísticas:

1. Substitutivas: substituir uma língua por outra, por exemplo, o imigrante absorvido pela cultura do país.

2. Deslocamento: possuir a língua materna, mas valer-se de outros idiomas de comunicação em diferentes esferas.

3. Aditiva ou de enriquecimento: manter e defender a língua nacional oferecendo a oportunidade do conhecimento de outras línguas para facilitar maior e melhor possibilidade de intercâmbio e compreensão de outros povos e culturas.

Em Cuba desenvolve-se uma política educacional dirigida ao fortalecimento da cultura e da língua nacional e, ao mesmo tempo, a que todos tenham a possibilidade de alcançar uma cultura geral integral, o que justifica os diferentes cursos de idiomas da televisão cubana em Universidade para Todos, dentre eles, o curso televisivo de português. A seguir, explicaremos de forma breve os antecedentes e o contexto nos quais se insere este curso.

Desde 1962, com a criação do novo sistema nacional de educação e o surgimento das escolas de idiomas para a aprendizagem de diversas línguas, o português é ensinado em vários

\footnotetext{
${ }^{2}$ No Editorial do Jornal Granma. Segunda-feira 3 de julho de 2000, segunda edição.
} 
centros docentes, fundamentalmente da capital do país. O ensino do português em Cuba e o uso dessa língua como ferramenta de trabalho estão relacionados com a política de amizade e solidariedade do nosso país com os países de expressão portuguesa, com as necessidades sociais e as demandas internacionais no campo das ciências, da política, da cultura e, com a satisfação espiritual dos indivíduos que estudam a língua.

O significativo desenvolvimento da indústria turística em Cuba nas últimas décadas exige cada vez mais a qualificação dos especialistas e funcionários da área, que inclui o conhecimento das línguas estrangeiras mantendo-se na preferência o português, logo abaixo do inglês e/ou francês. Mas, qual seria a causa dessa afirmação? Ao nosso ver, alguns fatores têm incidido e incidem aqui. Por exemplo, na década de 80 começaram a ser transmitidas em Cuba as telenovelas brasileiras que despertaram o interesse e serviram de motivação a numerosas pessoas para o estudo da língua e cultura desse país. Nas telenovelas --embora lamentavelmente dubladas em espanhol -- refletem-se determinados elementos culturais daquele povo semelhantes aos elementos da nossa cultura, o que facilita a compreensão mútua.

O português é uma das três línguas mais faladas no nosso continente e Brasil e Cuba mantêm excelentes relações de intercâmbio acadêmico, cultural e político-social há várias décadas. São dois países situados na mesma área geográfica e com uma impressionante proximidade no que se refere aos costumes e tradições populares, religião, alimentação, idiossincrasias.

O intercâmbio científico, acadêmico, a colaboração na esfera da saúde com pessoas de expressão portuguesa é elevado. Nos últimos anos tem se observado um crescente número de participantes de fala portuguesa em importantes Congressos e Eventos Internacionais celebrados em Cuba, como por exemplo, nos Congressos Internacionais de Educação Superior (Universidade 2004, 2006) e de Educação (Pedagogia 2003, 2005), onde o português foi considerado língua oficial, junto ao inglês e ao espanhol.

Na televisão cubana são exibidos numerosos documentários sobre a cultura brasileira, programas musicais e diferentes séries e míni-séries. Há uma forte presença em Cuba de numerosos grupos de artistas, intelectuais e poetas contemporâneos que passaram a ser cada vez mais conhecidos e respeitados- É elevado o número de filmes brasileiros projetados no nosso país, fundamentalmente durante o Festival de Cinema Latino-americano onde sucessivamente mais de um filme recebe importantes prêmios do júri. Todos esses dados referidos anteriormente são fatores que têm contribuído para a difusão do português no nosso país. 


\section{CURSO DE PORTUGUÊS EM UNIVERSIDADE PARA TODOS}

A Faculdade de Línguas Estrangeiras (FLEX) da Universidade de Havana, instituição responsável pela proposta inicial do curso, apresenta um quadro de quatro professoras de português, as quais trabalharam na preparação das condições indispensáveis para o desenvolvimento dessa experiência inédita: o curso de PLE em um novo contexto.

\section{OBJETIVOS}

Esse curso objetivou alcançar uma sensibilização, familiarização ou aproximação à língua e à cultura do Brasil. O marco televisivo permitiu contribuir à compreensão do funcionamento da língua, da pronúncia, da correspondência grafia/som, do uso de formas gramaticais para expressar intenções comunicativas em um nível básico-elementar. Permitiu conhecer o léxico básico usado em fórmulas elementares para interagir em situações comunicativas orais da cotidianidade. Foram dedicadas 54 horas à essa primeira emissão do curso de PLE- Estava dirigido a um número elevado, bem heterogêneo, de pessoas interessadas na aprendizagem da língua. O perfil daqueles que acompanharam o curso foi também muito heterogêneo em relação ao sexo, à idade e à profissão. Os professores recebiam cartas do público que manifestava o interesse pelas aulas enviando dúvidas gramaticais, sugestões e críticas construtivas. Escreveram crianças e jovens do ensino médio, pessoas de diferentes profissões e ocupações como operários, donas de casa e aposentados. Portanto a faixa etária flutuou entre os 12 e os 74 anos de idade. Outro dado distintivo também foi o local de residência destes telespectadores, visto que as cartas recebidas não eram só de habitantes da cidade de Havana, mas também de outras regiões do nosso país, do ocidente ao oriente.

\section{ESTRUTURA DO CURSO}

O curso teve início com a apresentação geral das semelhanças e diferenças nos níveis fonético-fonológicos entre o português e o espanhol. Posteriormente foram estudadas 9 unidades temáticas às quais, segundo o grau de complexidade, dedicaram-se 4, 6 ou 8 horas respectivamente. 
O conteúdo, as habilidades lingüísticas e socioculturais foram desenvolvidos através de diferentes tópicos partindo sempre de diálogos ou situações comunicativas (com apoio audiovisual) seguidos de perguntas de compreensão e a realização de atividades ou tarefas como repetições, leituras, exercícios de completar, de relacionar colunas, perguntas/ respostas, conversas, expressar de forma breve opiniões. Como temas tratados tivemos as atividades do dia-a-dia, o lar, as comidas, a família, a moradia, expressões culturais, os numerais e sua aplicação prática, atividades no passado, no futuro, nas férias e outros.

\section{ESTUDANTES}

Os alunos que participaram das aulas no estúdio foram selecionados fundamentalmente por dois critérios: Por um lado a própria voluntariedade deles e por outro, deveriam estar matriculados no nível básico de um dos cursos de português, ministrados em algum centro docente do país. Desse modo, foi selecionado um grupo heterogêneo de estudantes quanto ao sexo, idade e profissão. Lembremos que o público-alvo era heterogêneo, portanto tivemos telespectadores com diferente nível de conhecimento sociocultural e que se familiarizavam com os conteúdos sempre através das câmeras.

\section{MATERIAL DIDÁTICO}

A seleção e adoção do material didático a ser utilizado no curso constituíam uma das tarefas fundamentais. A Embaixada do Brasil em Cuba colocou à disposição dos professores materiais audiovisuais recebidos para esse primeiro curso da variante brasileira do português. Para a preparação das aulas foi utilizado o material didático Conhecendo o Brasil, um conjunto composto de duas fitas cassetes, três fitas de vídeo e o livro base.

Os diálogos do material audiovisual, editados, montados para cada tele-aula em correspondência com o tópico a introduzir, foram selecionados atendendo ao objetivo perseguido. Geralmente, o foco na gramática, seguindo Swain (1998), “realizou-se a partir do uso da língua em contexto significativo com o objetivo de chamar a atenção para a forma e significado dos enunciados”.

Devemos salientar que foi elaborado um caderno de exercícios "tablóide” de 15 páginas a ser usado pelos alunos que foi vendido à população a preço simbólico. Na capa 
observam-se fotos de personalidades do mundo lusófono, a saber: Fernando Pessoa, Machado de Assis, Jorge Amado e outras, assim como certas paisagens do Rio de Janeiro, e de Portugal e Brasília. No início foi feita uma pequena introdução sobre o curso televisivo de português. Em seguida, foram colocados diferentes tipos de exercícios e informações que apoiaram as aulas e o desempenho dos alunos. Alguns exercícios foram readaptados do livro didático e outros criados especialmente para o curso pelo coletivo de professores. Também foram incluídas informações sobre a vida e obra das personalidades da capa do tablóide e dados sobre os países de expressão portuguesa no mundo. Finalmente a apresentação na tela do curso e os slides mostrados foram personalizados com as cores da bandeira do Brasil: verde e amarelo.

\section{RESULTADOS}

O curso manteve-se no ar com duas freqüências semanais de uma hora, com retransmissões à noite e aos sábados durante 8 meses e, por solicitação da população, foi retransmitido novamente, em horário nobre às quartas-feiras.

Para falar dos resultados do curso de PLE lecionado através da televisão, poderíamos nos fundamentar nas cartas enviadas pelos telespectadores e também nas experiências pessoais de cada um dos professores que lecionaram as aulas. Um elemento que poderia resultar interessante é a correspondência recebida de milhares de pessoas que acompanharam o curso. Essas cartas indicam que o curso foi de ampla aceitação nacional. Outra evidência do resultado satisfatório é que a maioria dos telespectadores escreveu em português aplicando os conhecimentos adquiridos nesse curso. Constataram-se as interferências produzidas entre duas línguas próximas que têm sido apontadas pelos especialistas na bibliografia especializada. Para finalizar, gostaríamos de salientar que cerca de um milhão de alunos foram beneficiados em todo o país. 


\section{CONCLUSÕES}

O curso constituiu um elemento de motivação que impulsionou uma maior procura do ensino formal nas escolas de línguas do país. Foi de grande satisfação popular evidenciada por opiniões como: “foi um curso novo e diferente que permitiu sonhar” e "deu a possibilidade de viajar pelo Brasil e conhecer melhor os brasileiros e sua cultura”.

O novo tipo de curso ofereceu a oportunidade para as pessoas se aproximarem, uma vez mais, da cultura e da língua do Brasil, permitiu aumentar a visão intercultural e a melhor compreensão da outra cultura.

Constituiu uma motivação em si para muitas pessoas começarem a aprendizagem formal da nova língua em contexto de sala de aulas. Como resultado, houve um aumento significativo na procura de cursos de português em Cuba, fato que se verifica se atentamos aos indicadores numéricos das matrículas dos dois últimos anos escolares das escolas de línguas.

Prevê-se um segundo curso que vise ampliar os conhecimentos adquiridos na primeira etapa aprofundando os aspectos socioculturais do Brasil e dos países de expressão portuguesa em geral, satisfazendo aos interesses, motivações e fantasias dos aprendizes. Esse curso pretende contribuir para €om o desenvolvimento de uma cultura geral integral na população cubana.

\section{REFERÊNCIAS BIBLIOGRÁFICAS}

ALMEIDA FILHO, J.C.P. (org.). _ Parâmetros Atuais para o ensino de português Língua Estrangeira. Campinas, SP: Pontes, 1997.

ALMEIDA FILHO, J.C.P.- Dimensões Comunicativas no ensino de Línguas. Campinas: Pontes, 1993.

ALMEIDA FILHO, J.C.P. \& Lombello, L.C (orgs.) O ensino de Português para

Estrangeiros. Pressupostos para o planejamento de cursos e elaboração de materiais. Campinas, SP: Pontes, 1989. 
JUDICE, NORIMAR. Português para Estrangeiros: perspectivas de quem ensina. Niterói. Intertexto 2002.

\section{CONFERÊNCIAS, DISCURSOS E MESAS- REDONDAS.}

Editorial del periódico Granma. Lunes 3 de julio del 2000. Segunda edición.

Tabloide No. 4 Año 2001. Discurso pronunciado por Fidel Castro Ruz. Teatro Carlos Marx, 15 de marzo del 2001. Cuba.

Tabloide No. 16 Año 2001. El pensamiento y la conciencia pueden más que el terror y la muerte.

Conferencia Especial: “El desarrollo de la Educación en Cuba”. Dr. Luís Ignacio Gómez Gutiérrez. Ministro de Educación. Pedagogía 2001, Palacio de Convenciones de La Habana. Cuba.

Conferencia especial: El desarrollo de la Educación en Cuba. Dr. Luis I. Gómez. Congreso pedagogia, 2003. La Habana, Cuba.

Discurso pronunciado por el Presidente de la República de Cuba Dr. Fidel Castro Ruz, en la clausura del Congreso Pedagogía 2003, teatro "Carlos Marx", 7 de febrero del 2003.

Discurso pronunciado por el Presidente de la República de Cuba, Dr. Fidel Castro Ruz, acto de inauguración del curso escolar 2003-2004. Plaza de la Revolución, 8 de septiembre de 2003

La Universidad en la Construcción de un mundo mejor. Dr. Fernando Vecino Alegret. $4^{\circ}$ Congresso Internacional de la Educación Superior. CH. 2004.

Mesa Redonda Instructiva. La lengua como símbolo de identidad de los pueblos y naciones. Jueves, 10 de Junio del 2004.CH. Cuba. 
Mesa Redonda Internacional, 29 de Octubre del 2004. La Educación para la paz y la justicia social. Los avances en materia de educación que exhibe Cuba. La Habana, Cuba.

Cuaderno de italianística cubana. Año V. № 10. La Habana, mayo 2004. 